\title{
KAJIAN PENCEMARAN AIR TERHADAP KOMUNITI ORANG ASLI DI TASIK CHINI, PAHANG
}

\author{
IDA ROYANI AMRAN DAN RAHAYA MD. JAMIN*
}

Fakulti Perniagaan, Ekonomi dan Pembangunan Sosial, Universiti Malaysia Terengganu

*Corresponding author: rahaya.jamin@umt.edu.my

http://doi.org/10.46754/umtjur.2021.04.0012

\begin{abstract}
Abstrak: Pencemaran air di Tasik Chini, Pahang kian meruncing akibat pembangunan sekitar yang tidak terkawal menyebabkan kemusnahan rantaian makanan sekaligus mengancam kelangsungan hidup komuniti asli. Justeru, kajian telah dijalankan bagi mengenal pasti faktor, impak dan keberkesanan strategi dengan menggunapakai Teori Pengambilalihan. Selain itu, kajian ini dipilih untuk memenuhi kelompangan kajian terdahulu yang lebih menekankan kepentingan pengekalan biodiversiti flora dan fauna berbanding kajian terhadap kehidupan komuniti setempat. Maka, kajian deskritif tinjauan telah digunakan melalui kaedah pemerhatian, temu bual mendalam bersama empat orang informan, dianalisis secara transkripsi, triangulasi dan analisis kandungan. Dapatan kajian menunjukkan faktor pencemaran air berpunca daripada pembinaan empangan air, projek pembangunan, aktiviti pembalakan, aktiviti perlombongan dan hakisan tanih. Sementara, pertanian komersial juga menjejaskan kegunaan domestik, hidupan akuatik terganggu, perubahan sifat air, kehilangan sumber pendapatan, dan tahap kesihatan terjejas. Oleh itu, cadangan memperluaskan program advokasi seperti pengawalan pembuangan sampah sarap, pematuhan Penilaian Impak Alam Sekitar (EIA), penglibatan pihak awam dan swasta, pemantauan kesihatan, kesedaran awam, dan melakukan penyelidikan lanjutan. Kajian mendapati dua buah syarikat China mengeksport bijih besi yang diperoleh sekitar Tasik Chini menggunakan permit AP (Eksport dan Import) dari negeri lain, bukannya Pahang. Meskipun syarikat tersebut tidak mempunyai lesen melombong tetapi mereka mempunyai segala kelengkapan alatan memproses dan menjalankan operasinya hingga kini. Diharapkan isu pencemaran air di Tasik Chini dapat dipulihkan demi menjamin kelestarian sejagat.
\end{abstract}

Kata kunci: Tasik Chini, Pencemaran air, Komuniti asli, Degradasi dan Kualiti hidup.

Abstract: Water pollution in Tasik Chini, Pahang is getting worse due to uncontrolled surrounding development causing the destruction of the food chain as well as threatening the survival of indigenous communities. Thus, a study was conducted to identify the factors, impact and effectiveness of the strategy by applying the Acquisition Theory. In addition, this study was selected to fill the gaps of previous studies that emphasized more on the importance of conserving the biodiversity of flora and fauna than studies on local community life. Thus, the descriptive study of the survey was used through observation method, in-depth interviews with four informants, analyzed by transcription, triangulation and content analysis. The findings show that water pollution factors are caused by the construction of water dams, development projects, logging activities, mining activities and soil erosion. Meanwhile, commercial agriculture also affects domestic consumption, disrupted aquatic life, changes in water properties, loss of sources of income, and health levels are affected. Therefore, the proposal expands advocacy programs such as garbage disposal control, Environmental Impact Assessment (EIA) compliance, public and private sector involvement, health monitoring, public awareness, and conducting further research. The study found that two Chinese companies exported iron ore obtained around Tasik Chini using AP (Export and Import) permits from other states, not Pahang. Although the company does not have a mining license but they have all the equipment to process and run its operations to date. It is hoped that the issue of water pollution in Lake Chini can be remedied to ensure global sustainability.

Keywords: Lake Chini, water pollution, indigenous communities, degradation and quality of life. 


\section{Pengenalan}

Air adalah sumber utama yang menyokong kelangsungan sistem hayat manusia dan sistem biosfera. Sumber air bersih berpunca daripada badan-badan air iaitu sungai dan tasik penting untuk kegunaan harian seperti tujuan pembersihan, pertanian dan minuman. Jika kita kehilangan sumber air bersih di dunia ini, maka seluruh kehidupan akan mati. Kini, punca air bersih di sungai dan tasik semakin berkurangan akibat pencemaran air misalnya, tasik semulajadi seperti Tasik Chini perlu dipelihara kerana memberikan sumbangan yang tinggi terhadap kelangsungan biodiversiti, sumberdaya air, dan kecirian lokal komuniti asli. Justeru, kemampanan ekosistem dan subsistem ini perlu dipelihara sebagaimana termaktub dalam Akta Kualiti Alam Sekeliling 1974 (Mustaffa Omar et al., 2011).

Menurut Akta Kualiti Alam Sekeliling 1974, pencemaran air adalah apa-apa perubahan langsung atau tidak langsung kepada sifat-sifat fizikal, haba, biologi, atau radioaktif iaitu manamana bahagian alam sekitar yang melepaskan, mengeluarkan, atau meletakkan buangan ini sehingga menyebabkan suatu keadaan berbahaya dan memudaratkan kesihatan, keselamatan dan kebajikan pihak awam, atau kehidupan lain seperti burung, hidupan liar, ikan dan hidupan akuatik serta tumbuh-tumbuhan air. Terdapat enam parameter digunakan bagi menentukan Indeks Kualiti Air Negara (IKAN) iaitu $\mathrm{pH}$, permintaan oksigen biokimia (BOD), permintaan oksigen kimia (COD), oksigen terlarut (DO), ammonia-nitrogen $(\mathrm{NH} 3-\mathrm{N})$ dan jumlah pepejal terampai (TSS). Selain itu, kualiti air bagi setiap parameter diberikan dalam bentuk sub-indeks. Sub-indeks dikelaskan dalam bentuk peratusan iaitu dari nilai sifar hingga seratus. Nilai Indeks Kualiti Air Negara (IKAN) yang tinggi menunjukkan kualiti air adalah baik (Jabatan Alam Sekitar, 1998).

Selain itu, Tasik Chini disenaraikan sebagai Tapak Rizab Biosfera pada tahun 2009 di bawah program Manusia dan Biosfera (MAB) melalui inisiatif Pertubuhan Pendidikan, Saintifik dan Kebudayaan Pertubuhan Bangsa-Bangsa
Bersatu (UNESCO). Lembangan Tasik Chini menerima bekalan air daripada empat batang sungai iaitu Sungai Datang, Sungai Gumum, Sungai Perupok dan Sungai Melai dan aliran Sungai Chini sepanjang 4.8 kilometer turut bersambung dengan Tasik Chini dan Sungai Pahang malah Tasik Chini dikelilingi oleh paya air tawar dan hutan paya seluas 700 hektar (Pusat Penyelidikan Tasik Chini, 2013).

Keunikan tasik alam semula jadi seperti Tasik Chini terletak pada ekosistemnya yang terdiri daripada Hutan Paya Air Tawar, Hutan Dipterokarpa Tanah Pamah serta bukit malah kewujudan Hutan Tebing Sungai atau Hutan 'Levee' dipertengahan dan hilir Sungai Chini dengan dibarisi pelbagai spesies pokok tinggi dan matang seperti Pokok Ara, Cempedak Air, Mempari Sungai dan pelbagai spesies lain perlu dikekalkan. Oleh itu, Institut Penyelidikan Perhutanan Malaysia (FRIM) dengan kerjasama Jabatan Perhutanan Negeri Pahang (JPNP) perlu berganding bahu memba $\neg$ ngunkan kawasan ini. Justeru, terdapat beberapa kaedah yang dijalankan untuk memulih dan mengekalkan keindahan Tasik Chini seperti mengadakan Program Perhutanan Sosial dan menyediakan Prosedur Operasi Standard (SOP) berkaitan dengan aktiviti perlombongan dan pemuliharaan kesan perlombong. Seterusnya, penanaman semula pokok-pokok hutan dan penghijauan tebing-tebing kawasan perlombongan diperlukan untuk memastikan kegiatan itu dilaksanakan dengan lebih terkawal dan mematuhi garis panduan yang ditetapkan di kawasan aktiviti perlombongan (Jabatan Alam Sekitar, 2017).

Tasik Chini kaya dengan tanaman herba dan pohon untuk pembuatan minyak wangi seperti kayu gaharu dan candan. Tanaman ini dahulu hanya digunakan oleh masyarakat lokal untuk keperluan mereka sendiri. Kini, mereka mulai memanfaatkan tanaman herba itu secara lebih ekonomi dengan adanya campur tangan dari pihak luar yang mengeksplotasikan hasil hutan secara besar besaran. Misalnya, minyak wangi yang diperbuat daripada kayu gaharu dan candan turut dieksport ke luar negara seperti ke Timur Tengah. Salah satu projek tanaman herba ini di 
bawah Funding United Nation Development Programe (UNDP) ialah mempromosikan tanaman herba kepada para pelancong supaya mereka dapat menjelajahi keunikan flora dan fauna di Tasik Chini, Pahang (Cahyo, 2011).

Kini, Tasik Chini mengalami degradasi akibat perlombongan dan pembalakan. Tasik Chini yang dulunya berseri dengan bunga teratai sebagai ikon Tasik Chini yang berkembang mekar dari bulan Jun hingga Januari setiap tahun kini diambang kemusnahan. Pelbagai usaha pemuliharaan dan peningkatan kualiti air dijalankan untuk mengembalikan keindahan bunga-bunga teratai di Tasik Chini. Apatah lagi, keindahan Tasik Chini sering dikaitkan dengan kisah rakyat "Lagenda Tasik Chini" dengan jolokan "Naga Sri Gumum" bersisik besi masih dipercayai hingga kini oleh komuniti asli di situ. Oleh itu, langkah-langkah pemeliharaan dan pemuliharaan perlu digiatkan agar komuniti asli dapat meneruskan kehidupan mengikut sosiobudaya dan adat resam mereka (Pusat Penyelidikan Tasik Chini, 2013).

Hal ini dibuktikan melalui kajian lepas yang banyak membincangkan kepentingan pengekalan keindahan biodiversiti flora dan fauna di Tasik Chini seperti kajian Mohd Ekhwan Toriman (2012), Sulong Mohamad (2006) dan Shahfina Mohd Jaafar (2013). Namun, kajiankajian lepas kurang memberi penekanan pada aspek kualiti hidup komuniti Orang Asli yang merupakan penghuni tetap di Tasik Chini, Pahang. Ini kerana, komuniti Orang Asli di Tasik Chini merupakan golongan minoriti di Malaysia. Golongan ini juga sering dipinggirkan oleh masyarakat luar kerana beranggapan tidak menyumbangkan kepentingan yang besar dari segi ekonomi, politik dan sosial. Perkara ini dibuktikan dengan apabila adanya program mahupun aktiviti menjaga dan memulihara Tasik Chini komuniti Orang Asli tiada tempat untuk mereka melibatkan diri dalam aktiviti tersebut. Dalam konteks ini, penglibatan orang asli diperlukan kerana mereka telah mendiami kawasan Tasik Chini berabad lama dan mengetahui lebih mendalam berkaitan Tasik Chini. (Mustaffa Omar, 2011). Justeru itu, peranan dan kepentingan komuniti Orang Asli tidak sepatutnya diabaikan kerana mereka lebih mengetahui dan berpengalaman tentang kecirian lokal, geobudaya dan kandungan khazanah Tasik Chini ini.

Di samping itu, kajian ini turut menyumbang kesedaran masyarakat dan kepentingan penglibatan orang asli dalam menangani pencemaran air di Tasik Chini, Pahang. Ini kerana dalam kegelutan kita meraih keuntungan ekonomi daripada hasil bumi seperti aktiviti perlombongan bijih besi dan pembalakan, kita sering lalai dan terleka akan kesannya terhadap alam sekitar khususnya terhadap kualiti air. Hal ini menyebabkan golongan minoriti seperti komuniti Orang Asli kehilangan sumber air bersih dan makanan seperti ikan air tawar untuk kelangsungan hidup apatah lagi adat resam mereka diambang kepupusan. Menerusi kajian ini masyarakat, pemaju, dan pihak berkepentingan akan lebih peka setiap tindakan berkaitan dengan alam sekitar yang ingin mereka terokai.

\section{Bahan dan Kaedah}

Pendekatan Teori Pengambilalihan (Succession Theory) yang dikemukakan oleh Clements pada tahun 1916 digunakan dalam kajian ini kerana bersesuaian dengan kajian yang dilaksanakan. Bahkan turut mendedahkan pengkaji untuk mempelajari kaedah penyelidikan kualitatif yang berbentuk deskriptif tinjauan dan tiga teknik iaitu pemerhatian, temu bual mendalam, serta menganalisis beberapa dokumen data primer seperti temu bual mendalam dan data sekunder seperti buku dan jurnal bagi mendapatkan kesahihan maklumat.

Teori Pengambilalihan merupakan perubahan atau perpindahan yang berlaku di sesuatu kawasan dan berpunca dari pelbagai faktor. Bahkan, memaksa seseorang atau kelompok untuk melakukan perubahan tersebut. Pengkaji mendapati teori ini bersesuaian dengan situasi yang berlaku di Tasik Chini kerana pembinaan kunci air (empangan) di kawasan berkenaan telah menyebabkan berlakunya 
perubahan yang ketara bukan sahaja terhadap alam sekitar bahkan kepada penduduk setempat. Pembinaan kunci air berkenaan menyebabkan operator bot di Kg Belimbing yang merupakan pintu masuk para pelancong ke Tasik Chini kehilangan sumber pendapatan kerana para pelancong memasuki kawasan Tasik Chini di kawasan berhampiran dengan kunci air yang di dominasikan oleh pengusaha bot di Tasik Chini. Selain itu, sukan tahunan iaitu kayak tidak dilakukan lagi di Tasik Chini ekoran perubahan air tasik yang telah kotor kesan daripada sampah sarap yang di hanyutkan dari Sg Pahang semasa kunci air dibuka (Sulong Mohamad et al., 2006).

Teori ini juga bertepatan dengan perubahan dalam pembandaran dan pemodenan yang pesat dilaksanakan berhampiran tasik tersebut. Justeru, keadaan ini memberi pelbagai cabaran dan masalah terhadap komuniti Orang Asli di Tasik Chini malahan ekosistem tasik tersebut turut terganggu. Selain itu, Penerokaan kawasan berhampiran dengan Tasik Chini untuk tanaman komersial seperti ladang getah dan kelapa sawit menyebabkan biologi dan khazanah semula jadi diambang kemusnahan. Oleh itu, setiap sesuatu perubahan atau pengambilalihan perlu diambil kira kesannya terhadap komuniti setempat dan alam sekitar (Mustaffa Omar et al., 2011).

Penyelidik menggunakan pendekatan penyelidikan kualitatif dalam melaksanakan kajian ini kerana pendekatan ini mampu memberikan jawapan yang tepat dan terperinci. Selain itu, penyelidikan kualitatif merujuk kepada kajian yang memerlukan pemerhatian yang teliti. Bahkan, kajian kualitatif tidak memerlukan bilangan responden yang ramai tetapi memperolehi maklumat yang berkualiti, tepat dan sahih. Kajian pencemaran air terhadap komuniti orang asli di Tasik Chini, Pahang yang melibatkan sumber air dan manusia. Melalui pendekatan kualitatif maklumat yang dikongsi adalah pelbagai (Chua, 2011).

Reka bentuk kajian adalah pelan tindakan yang memperlihatkan secara terperinci bagaimana sesuatu kajian itu dijalankan. Selain itu, reka bentuk kajian berfungsi sebagai panduan bagi membantu penyelidik dalam proses memungut, menganalisis dan membuat pentafsiran hasil daripada penyelidikan yang dijalankan berkenaan kajian pencemaran air terhadap komuniti orang asli di Tasik Chini, Pahang. Penyelidikan yang dijalankan ini merupakan kajian deskriptif yang bermatlamat untuk meninjau dan meneroka sesebuah masalah kajian. Selain itu, reka bentuk kajian deskritif tinjauan turut mendedahkan pengkaji tentang keadaan sebenar di kawasan kajian seterusnya melihat sendiri pencemaran air di Tasik Chini terhadap komuniti setempat dan meneroka faktor dan keberkesanan langkah dalam mengatasi masalah ini. Oleh itu, pengkaji mendapat gambaran awal mengenai dapatan kajian di samping memperolehi maklumat tambahan (Sabitha, 2006).

Populasi kajian terdiri daripada empat orang informan iaitu seorang pegawai jurutera JPS, seorang pegawai perubatan di Klinik Chini, dua orang penduduk orang asli yang tinggal di kawasan Tasik Chini. Keempatempat informan ini merupakan informan utama kajian bagi mendapatkan maklumat tentang impak dan faktor berlakunya pencemaran air serta keberkesanan langkah untuk menangani masalah ini agar keindahan Tasik Chini terus terpelihara dengan baik.

Kajian ini turut menguna pakai kaedah pemerhatian dan kaedah temu bual mendalam. Bahkan turut menggunakan kaedah analisis dokumen daripada Jabatan Pengairan dan Saliran Malaysia (JPS) serta Klinik Kesihatan Chini dan sumber sekunder seperti kajian daripada jurnal dan buku agar dapat mengumpul data yang efisyen dalam kajian ini. Bukan itu sahaja, kesemua kaedah ini dianggap penting oleh penyelidik kerana mempunyai sumbersumber boleh digunakan untuk menjadi bahan bukti di dalam hasil kajian. Oleh itu, dengan adanya kaedah ini dapat membantu penyelidik untuk mengkaji kajian pencemaran air terhadap komuniti orang asli di Tasik Chini, Pahang.

Kutipan data dalam kajian ini adalah pendekatan kualitatif berbentuk deskriptif tinjauan di kawasan kajian iaitu Tasik Chini. Kutipan data ini dilakukan melalui beberapa cara 
iaitu kaedah pemerhatian, temu bual mendalam, analisis dokumen dan triangulasi data.

Kaedah pemerhatian merupakan suatu kaedah yang dilakukan semasa proses temu bual bersama informan. Selain itu, kaedah pemerhatian juga alternatif yang wajar dilaksanakan dalam proses mendapatkan dan mengumpul maklumat. Bahkan, penyelidik dapat mengamati sesuatu perbuatan atau tingkah laku informan semasa menjalankan kajian ini untuk melihat reaksi informan agar tiada unsur penipuan seperti bahasa tubuh, mimik muka dan gerakan mata. Oleh itu, melalui kaedah pemerhatian dapat memantapkan lagi penyelidikan yang dijalankan agar penyelidik mendapat jawapan yang bernas.

Terdapat dua kategori dalam kaedah temu bual iaitu temu bual secara mendalam (depth interview) dan melalui kumpulan fokus (focus group). Temu bual secara mendalam kebiasaannya melibatkan dua orang sahaja seperti seorang penyelidik dengan seorang informan. Manakala bagi temu bual secara kumpulan melibatkan sekumpulan orang seperti seorang penyelidik dengan beberapa orang informan (Yusof, 2003). Namun dalam kajian ini penyelidik menggunakan temu bual secara mendalam kerana lebih bersesuaian dan memperoleh jawapan lebih bernas (Taylor \& Bogdan, 1984). Bahkan, melalui kaedah temu bual mendalam penyelidik dapat memperoleh pengetahuan yang meluas dengan cara mendalami sesebuah penceritaan tertentu. Oleh itu, dalam kajian ini penyelidik menemu bual empat orang informan yang terdiri daripada seorang pegawai jurutera JPS, seorang pegawai perubatan di Klinik Chini, dua orang penduduk orang asli yang tinggal di kawasan Tasik Chini.

Analisis data adalah proses memudahkan data menjadi bentuk mudah di baca dan diterjemahkan. Selain itu, analisis data merupakan usaha mencari dan menyusun secara sistematik catatan hasil observasi, wawancara dan lain-lain untuk meningkatkan pemahaman tentang penyelidikan yang dijalakankan dengan teliti (Miles \& Huberman 1994). Terdapat lima penganalisasian data yang diperlukan dalam kajian ini antaranya (i) Verbatim iaitu satu kaedah untuk mengumpul data yang diperoleh daripada informan; (ii) Pengekodan iaitu mengkodkan setiap maklumat penting yang dinyatakan oleh informan; (iii) Transkripsi iaitu menaip setiap perkataan yang dinyatakan oleh informan sepaanjang sesi temu bual dijalankan; (iv) Triangulasi iaitu satu kaedah yang bertujuan untuk menganalisis setiap maklumat yang diperolehi dan; (v) Analisis kandungan iaitu memudahkan data agar mudah dibaca, difahami dan ditafsir.

\section{Hasil dan Perbincangan Kajian}

Pencemaran air terbahagi kepada dua bahagian iaitu punca tetap dan punca tidak tetap. Pencemaran daripada punca tetap berlaku akibat pelepasan effluen yang dilepaskan ke alur air atau sungai melalui limpahan atau paip manakala punca tidak tetap adalah berpunca daripada air larian hujan (surface run off) yang membawa pencemar ke badan-badan air (Jabatan Alam Sekitar, 2018). Antara faktor yang telah dibincangkan adalah pembinaan empangan, projek pembangunan, aktiviti pembalakan, aktiviti perlombongan, hakisan tanih dan pertanian komersial. Kesemua faktor ini berjaya dikenal pasti hasil daripada temu bual mendalam bersama key informan dan maklumat tambahan daripada sumber sekunder.

\section{Pembinaan Empangan/Kunci Air}

Antara faktor yang paling ketara memberi impak kepada kualiti air tasik adalah pembinaan empangan yang dibina di Kuala Sg. Chini. Pembinaan empangan air ini mengakibatkan penggerakan aliran air menjadi terjejas dan perlahan lalu menyebakan pembiakan bakteria di dalam air tasik. Selain itu, pembinaan empangan air juga menyebabkan sampah sarap memasuki kawasan air tasik sewaktu musim hujan dan banjir. Bahkan, sejenis rumpai dikenali sebagai rumpai ekor kucing turut membiak dalam badan air tersebut. Pembiakan rumpai ekor kucing ini mampu menjejaskan pembiakan beberapa spesis tumbuhan lain seperti teratai yang menjadi ikon 
Tasik Chini dengan menutupi permukaan tasik (Mustaffa Omar et al., 2011).

\section{Projek Pembangunan}

Kewujudan projek pembangunan ini sememangnya memberi kesan kepada alam sekitar khususnya pencemaran air. Namun begitu, isu ini dianggap tidak membimbangkan memandangkan masalah pepejal terampai merupakan masalah kedua punca kepada pencemaran air. Penduduk melihat bahawa masalah pencemaran tasik ini berpunca daripada aktiviti pelancongan di kawasan Tasik Chini. Kehadiran pelancong luar dan para pelawat sememangnya memberi keuntungan kepada penduduk setempat. Namun begitu, jika tidak dikawal lebih awal kawasan tasik turut mengalami kemusnahan kesan daripada sampah sarap termasuk botol dan plastik dibuang ke dalam tasik. Malahan, kegagalan pihak berwajib dalam menangani masalah ini menyebabkan keadaan menjadi lebih parah dan Tasik Chini akan hilang ditelan zaman.

\section{Aktiviti Pembalakan}

Kesan pembalakan yang pesat di sekitar Tasik Chini telah menyebabkan penduduk setempat kehilangan sumber hutan di mana sumber ini digunakan bagi tujuan perubatan. Pembalakan juga memberi impak kepada alam sekitar dari segi kegondolan bukit yang menyebabkan bahagian tebing mudah terhakis lalu menyebabkan larian air berlumpur memasuki badan-badan air. Menurut Wan Junaidi Tuanku Jaafar (2017) tiada lesen pembalakan yang dibenarkan dalam kawasan hutan simpan kekal mahupun rezab pelancongan atau tanah kerajaan berhampiran Tasik Chini, Pahang.

\section{Aktiviti Perlombongan}

Aktiviti perlombongan ini memberi kesan yang sangat ketara kepada badan air kerana kegiatan ini dilaksanakan tanpa mengikut piawai perundangan yang sebenar dengan melihat aspek jarak sesuatu projek. Bahkan keadaan ini menjadi lebih parah tanpa ada sebarang tindakan susulan yang dilaksanakan oleh pihak yang terlibat. Perkara ini disokong oleh kajian lepas seperti kajian Cahyo, (2011) iaitu penurunan kualiti air di Tasik Chini berpunca dari perlombongaan bijih besi secara sah mahupun yang tidak sah. Perlombongan secara sah dilaksanakan di kawasan luar Tasik Chini dan agak jauh lokasinya dari tasik. Akan tetapi, perlombongan bijih besi secara haram terletak di hutan sekitar Tasik Chini. Perlombongan bijih besi yang tidak sah dan dilaksanakan bersebelahan kawasan tasik menyebabkan air tasik tercemar dengan mengandungi bijih besi logam.

\section{Hakisan Tanih}

Faktor pencemaran air adalah berpunca daripada hakisan yang berlaku ditebing tasik. Keadaan badan air menjadi lebih parah apabila berlakunya musim hujan yang lebat dan berpanjangan. Malahan, keadaan ini perlu dipandang serius oleh semua pihak sama ada terlibat secara langsung mahupun tidak untuk bersama-sama membasmi masalah ini terutamanya di bahagian tebing tasik yang struktur tanahnya kian melonggar.

\section{Pertanian Komersial}

Terdapat juga di sekitar Tasik Chini pertanian komersial untuk ladang kelapa sawit dan getah, anjuran FELDA, RISDA dan MUIP. Pada permulaannya, aktiviti pertanian ini dilakukan di kawasan yang telah ditetapkan oleh kerajaan. Namun begitu, aktiviti pertanian ini telah berleluasa dilakukan pada kawasan berhampiran tasik berkenaan. Kesannya, apabila musim hujan lebat larian air berlumpur yang membawa kandungan racun dan baja tanaman telah diresap oleh tanah dan dialirkan ke dalam badan tasik. Tambahan pula, aktiviti tradisi penduduk setempat seperti memburu binatang juga terjejas kesan daripada pembukaan kawasan pertanian secara berleluasa. 


\section{Menjejaskan Kegunaan Domestik}

Pada masa dahulu sekitar 60-an sehingga 80-an, air tasik boleh diminum begitu sahaja kerana bersih namun begitu, sejak tahun 2000 keadaan air semakin keruh dan tidak lagi selamat untuk diminum. Akan tetapi penduduk terpaksa menggunakan air tersebut yang dipam ke telaga untuk tujuan domestik. Namun, apabila hujan berterusan, air tasik lebih keruh berikutan lumpur dari bukit yang ditarah mengalir masuk ke tasik menyebabkan gangguan air kepada penduduk. Sehubungan itu, diharapkan kerajaan mengambil perhatian serius terhadap masalah penduduk setempat dan memantau kegiatan penerokaan tanah di sekitar Tasik Chini.

\section{Hidupan Akuatik Terganggu}

Pencemaran air yang berlaku menyebabkan sumber makanan utama penduduk setempat semakin berkurangan. Hal ini berlaku ekoran pembinaan empangan yang menyebabkan hidupan akuatik khususnya ikan menyusuri keluar dari Tasik Chini melalui empangan tersebut. Malangnya, spesis-spesis ikan tersebut tidak lagi dapat memasuki Tasik Chini kerana paras air yang berbeza setiap masa. Malahan, keenakan ikan air tawar di Tasik Chini kini sudah tidak sama seperti dahulu kerana dipercayai berbau minyak dan tanah yang mampu menghapuskan rasa asal ikan tersebut. Bukan itu sahaja, kesan dari pencemaran air ini menyebabkan penduduk terpaksa keluar dari perkampungan mereka untuk memperoleh sumber makanan mentah yang segar kerana sumber makanan di tasik kian berkurangan.

\section{Perubahan Sifat Air}

Kesan pencemaran air di Tasik Chini juga menyebabkan perubahan warna air tasik. Ini kerana larian air dari kawasan aktiviti perlombongan dan pembalakan yang giat dijalankan berhampiran badan air tersebut. Penduduk juga menyatakan perubahan warna dari dahulu dan sekarang di mana dahulu air tasik tersebut berwarna biru dan boleh melihat dengan jelas keadaan dasar tasik tersebut.
Namun begitu, kesan daripada kerakusan tangan manusia sekeliling telah menyebabkan warna air tasik berubah menjadi merah dan kehitaman tanah kesan daripada angkutan sedimen ke dalam tasik.

\section{Kehilangan Sumber Pendapatan}

Kesan pencemaran yang berlaku di Tasik Chini bukan sahaja meninggalkan kesan yang mendalam terhadap kualiti air tersebut malahan sumber pendapatan penduduk turut terkesan daripada isu ini. Para pelancong tidak lagi meletakkan Tasik Chini sebagai destinasi perlancongan mereka kerana isu alam sekitar yang kian merosot dan keadaan ini menyebabkan penduduk setempat khususnya yang menyediakan perkhidmatan bot menyusuri Tasik Chini kehilangan sumber pendapatan mereka.

\section{Tahap Kesihatan Terjejas}

Impak pencemaran air telah menyebabkan hidupan akuatik khususnya ikan mengalami masalah seperti berkudis. Penyakit ikan ini dipercayai berpunca daripada sisa tercemar dalam badan air. Namun begitu, penyakit ikan bukan sesuatu penyakit yang kronik kerana masih boleh dimakan oleh penduduk setempat. Selain itu, terdapat juga penduduk setempat yang mengalami masalah kesihatan dari segi cirit birit dan muntah-muntah. Walaupun begitu, masalah kesihatan ini bukan sematamata berpunca daripada masalah air di kawasan tersebut tetapi turut dikaitkan dengan isu cuaca dan amalan gaya hidup masyarakat setempat.

\section{Pengawalan Pembuangan Sampah}

Pencemaran air di Tasik Chini dapat dikurangkan dengan menggunakan strategi yang berkesan seperti membakar sampah-sampah tersebut. Keadaan ini bukan sahaja mampu mengurangkan sejumlah besar sampah sarap akan tetapi dapat menghindari penduduk setempat daripada aedes. Sekali gus penyakit Denggi dan Chikungunya dapat dikurangkan. Selain itu juga, amalan 
tradisi ini menurut informan wajar dilakukan kerana bilangan penduduk yang tidak ramai dan sekiranya berlaku pencemaran udara hanya dalam jangka masa yang singkat sahaja.

\section{Penilaian Impak Alam Sekitar (EIA)}

Penduduk meletakkan hasrat yang tinggi dalam pemulihan kualiti air tasik tersebut dengan cara menutup mahupun menambah baik sistem empangan agar sistem saliran air dapat berfungsi dengan baik. Sistem empangan sememangnya satu alternatif yang baik untuk keseimbangan kuantiti air dalam sesebuah badan air. Namun demikian, perancangan yang tidak sesuai telah menyebabkan sesebuah keadaan itu bukan bertambah baik malahan semakin serius. Oleh itu, setiap perancangan yang ingin dilaksanakan terutamanya yang melibatkan badan air perlu dikaji terlebih dahulu di peringkat EIA agar dapat dielakkan berlakunya kesan negatif yang ketara terdahap alam sekitar.

\section{Penglibatan Pihak Awam dan Swasta}

Jabatan Pengairan dan Saliran (JPS) merupakan agensi yang bertanggungjawab dalam pemulihan sistem-sistem saliran di Tasik Chini. Bahkan agensi tersebut pernah menjalankan kegiatan pemulihan alam sekitar seperti membersihkan badan air yang tercemar dengan sisa pembalakan. Selain itu, pihak swasta juga berperanan dalam pemulihan Tasik Chini dengan mengadakan program tanaman tutup bumi dengan kerjasama pihak FRIM. Bukan itu sahaja, kebanyakan program yang dilaksanakan melibatkan penyertaan penduduk setempat kerana penduduk setempat mempunyai penerimaan yang baik untuk bersama-sama menjaga alam sekitar selain dapat mendengar pendapat mereka mengenai pencemaran ini.

\section{Pemantauan Kesihatan}

Pihak Kementerian Kesihatan Malaysia (KKM) sangat berperanan ketika banjir di Tasik Chini. Banjir terbaharu adalah pada tahun 2016 di mana sekeliling kawasan perumahan penduduk Orang
Asli tenggelam dan terpaksa menggerakkan bantuan daripada pihak KKM untuk pergi ke kawasan berkenaan bagi melakukan pemeriksaan kesihatan kerana kebiasaanya apabila banjir, penduduk mudah terdedah dengan pelbagai jenis penyakit. Penyakit yang ketara sekali adalah cirit birit. Bahkan, Pegawai Sains Makanan juga turut mengambil bahagian ketika berlakunya banjir dengan memberi pendedahan dan penerangan tentang penyediaan makanan dan penjagaan kesihatan ketika banjir. Oleh itu, pemantauan kesihatan oleh agensi terlibat adalah sangat penting bagi memastikan tahap kesihatan penduduk masih dalam keadaan baik.

\section{Kesedaran Awam}

Kesedaran orang awam terhadap alam sekitar masih ditahap kurang memuaskan ekoran kurang pendedahan terhadap alam sekitar kepada para pelancong. Oleh itu, pihak yang berperanan dalam mengawal isu ini adalah pemandu bot itu sendiri kerana meraka lebih terdedah kepada para pelancong. Pemandu bot tidak seharusnya mendiamkan diri sekiranya melihat para pelancong membuang sampah ke dalam tasik. Pemandu bot seharusnya menegaskan bahawa tidak dibenarkan membuang sampah ke dalam tasik. Hal ini menunjukkan sikap yang positif kerana sedikit sebanyak mampu mengurangkan pencemaran air di Tasik Chini.

\section{Kesimpulan}

Kesimpulannya, dapat dirumuskan bahawa penyelidikan mengenai kajian pencemaran air terhadap komuniti Orang Asli di Tasik Chini, Pahang telah memberi gambaran yang jelas mengenai kajian pencemaran air ini sekali gus ketiga-tiga objektif kajian terjawab. Selain itu, kajian ini juga banyak menyentuh isu-isu yang tidak diterbitkan iaitu impak daripada aktiviti sekeliling yang telah memusnahkan habitat flora dan fauna serta degradasi kualiti hidup penduduk setempat. Justeru, pihak berwajib perlu melakukan pemantauan, penguatkuasaan dan mengenakan tindakan undang-undang kepada mereka yang menjalankan aktiviti menjejaskan kualiti air. Misalnya, pemantauan 
berterusan terhadap aktiviti di kawasan badan air mampu mencegah pemaju dan pengusaha tanah daripada melanggar peraturan yang telah ditetapkan oleh kerajaan. Bahkan, mereka lebih berwaspada untuk mengeksplotasi hasil hutan ekstensif kepada mengawal dan mengekalkan sumber air bersih dan terpelihara.

\section{Rujukan}

Akta Kualiti Alam Sekeliling. (1974). Kuala Lumpur: Percetakan Nasinal Malaysia Berhad.

Cahyo, S. (2011). Pengetahuan Ekologi Tradisional Masyarakat Orang Asli Jakun. Jurnal Ilmu Sosial dan Ilmu Politik, 15, 5567.

Chua Y. P. (2011). Kaedah dan Statistik Penyelidikan: Kaedah Pendidikan. Kuala Lumpur: McGraw Hill.

Clements, F. E. (1916). Plant succession: An analysis of the develop-ment of vegetation. Carnegie Inst. of Washington.

Jabatan Alam Sekitar. (2018). Laporan Kualiti Alam Sekitar 2018. Kementerian Sains, Teknologi dan Alam Sekitar Malaysia, Kuala Lumpur.

Jabatan Alam Sekitar. (2017). Laporan Kualiti Alam Sekitar 2017. Kementerian Sains, Teknologi dan Alam Sekitar Malaysia, Kuala Lumpur.

Jabatan Alam Sekitar. (1998). Laporan Kualiti Alam Sekitar 1998. Kementerian Sains, Teknologi dan Alam Sekitar Malaysia, Kuala Lumpur.

Jabatan Alam Sekitar.(1997). Laporan Kualiti Alam Sekitar 1997. Kementerian Sains, Teknologi dan Alam Sekitar Malaysia, Kuala Lumpur.

Miles, M. B., \& Huberman, A. M. (1994). Qualitative Data Analysis, $2^{\text {nd }}$ ed., pp.1012. Newbury Park, CA: Sage.
Mustaffa, O., Zanisah, M., \& Ishak Y. (2011). Strategi tradisional komuniti Jakun Tasik Chini, Pahang mengurus sumber semulajadi secara lestari. Jurnal Sains Sosial dan Kemanusiaan, 6(2), 239254.

Pusat Penyelidikan Tasik Chini, UKM. (2013). Kenali Rizab Biosfera UNESCO yang pertama di Malaysia. Muat turun dari https://pptc.my/en/2013.

Sabitha Marican. (2006). Penyelidikan Sains Sosial Pendekatan Pragmatik. Batu Caves, Selangor: Edusystem Sdn. Bhd.

Sulong, M., \& Mohd, E. T. (2006). Implikasi struktur kunci air ke atas aktiviti pelancongan dan penduduk di sekitar Sungai Chini dan Tasik Chini, Pekan Pahang. Jurnal Elektronik Fakulti Sains Sosial dan Kemanusiaan, 1(1),148-159.

Taylor, S. J., \& Bogdan, R. (1984). Introduction to Qualitative Research Methods: The Search for Meanings. Second Edition. John Wiley and Sons. Toronto.

Toriman M. E., Kamarudin, A., Aziz, A., MdDin, H., Marcus-Ata, F., Abdullah, N. M., \& Mokhtar, A. M. (2012). Pengurusan sedimen terhadap sumber air bersepadu: satu kajian kes di Sungai Chini, Pekan, Pahang. Jurnal e-Bangi, 7, 267-283.

Wan, J. T. J. (2017). Kerajaan rancang gubal undang-undang pengurusan sumber air. Retrieved from http://www.astroawani. com/video-malaysia/kerajaan-rancanggubal-undang-undang-pengurusan-sumberair 29/11/2017.

Yusof, R. (2003). Penyelidikan Sains Sosial (Social Science Research). Pahang, Malaysia: PTS Publications \& Distributors. 
